\title{
Random generation: Number of symbols to be randomized and time per response'
}

PATRICIA A. WARREN AND ROBERT E. MORIN KENT STATE UNIVERSITY

\begin{abstract}
Attempts to randomize digits are relatively less successful the greater the number of digits to be randomized and the faster the rate at which responses must be made. However, increases in the number of digits and/or response rate result in improvements in information generated per unit time.

\section{Problem}

Tune (1964) has summarized the effects of a number of variables related to man's ability to act as a random generator. Conclusions regarding two of the variables, number of symbols to be randomized andresponse rate, are based on the data of Baddeley (1962) who found poorer randomization of letters and numerals with larger alphabets and with less time per response. Baddeley interprets these data as support for his hypothesis that man is an information generator of limited capacity.

Two problems arise in evaluating Baddeley's data and conclusions. First, his Ss generated relatively short sequences of responses under each experimental condition. The number of observations was not sufficient for the calculation of conventional information measures, nor was it feasible to examine frequencies of trigrams and tetragrams. A second difficulty arises in the interpretation of Baddeley's hypothesis. The nature of the presumed limits on man's ability to generate information is not clarified. Most plausible is the interpretation that a limit may exist on the amount of information that can be generated per unit time. Such a hypothesis would imply the existence of a point beyond which neither increases in response rate nor increases in size of the symbol set would cause any further improvement in the amount of information generated per unit time. Baddeley's data do not permit an evaluation of this implication. The present experiment was designed to examine more completely the effects of number of symbols to be randomized and time per response upon random generation.

\section{Method}

The Ss were two male graduate students in the Department of Psychology at Kent State University. Both were sophisticated in the meaning and use of random numbers.

Ss randomized two digits $(1,2)$, four digits $(1-4)$, or eight digits (1-8) at rates of one response every $.25, .50$, or $.75 \mathrm{sec}$. Each $\mathrm{S}$ was tested under the nine experimental conditions defined by all combinations of set size and time per response. Approximately 1,000 responses were collected from each $\mathrm{S}$ in each condition for three consecutive weeks. Thus, a S produced 9,000 responses per week and 27,000 responses over the course of the experiment. There were three experimental sessions a week. At each session data were collected under three experimental conditions. The order of conditions within a week was random within the restriction that each possible number of digits and each possible time per response was used exactly once at every experimental session.

Ss' responses were verbal and were recorded on an office dictating machine. Responses were paced by "clicks" produced by an interval timer. There were 2-min. rests between blocks of 500 responses and 5-min. rests between conditions. The testing period for one day lasted approximately $45 \mathrm{~min}$.

Information measures were calculated from the 1,000 responses collected each week in each condition. The general mode of analysis was like that described by Attneave (1959, Chap. 2) and was sensitive to sequential dependencies in the response series. Measures were computed not only from the frequencies of single digits but also from frequency distributions of longer overlapping response strings (digrams, trigrams, and tetragrams). All frequency distributions and information measures were calculated on an IBM 1620 computer.

The number of distinct strings of length $n$, when $k$ different symbols have been randomized, is $\mathrm{k}^{\mathrm{n}}$. Miller (1955) has demonstrated a bias in the information measure, a bias which becomes larger as $\mathrm{k}^{\mathrm{n}}$ increases relative to the number of observations made. In the present experiment no direct correction was made for the bias. Instead, sequences generated by Ss were compared to sequences derived from a random number table. The random sequences provide a reference with an equivalent degree of bias. Information maxima were also calculated for purposes of reference. The maximum amount of information in a string of length $\mathrm{n}$ is $\log _{2} \mathrm{k}^{\mathrm{n}}$ bits if the number of observations is very large. If eight symbols are randomized $(\mathrm{k}=8)$ and trigram frequencies $(\mathrm{n}=3)$ are counted, a trigram could contain up to $\log _{2} 512=9$ bits of information. To determine the maximum amount of information with only 1,000 observed trigrams, it was assumed that each of the 512 distinct trigrams occurred with as near equal frequencies as possible-in this case, that 488 trigrams occurred twice and that 24 trigrams occurred once. These frequencies result in a maximum of 8.990 bits of information per trigram, slightly less than the 9 bits possible with many more responses.

\section{Results}

Changes from week to week in the amount of information generated within a condition were small and incon- 

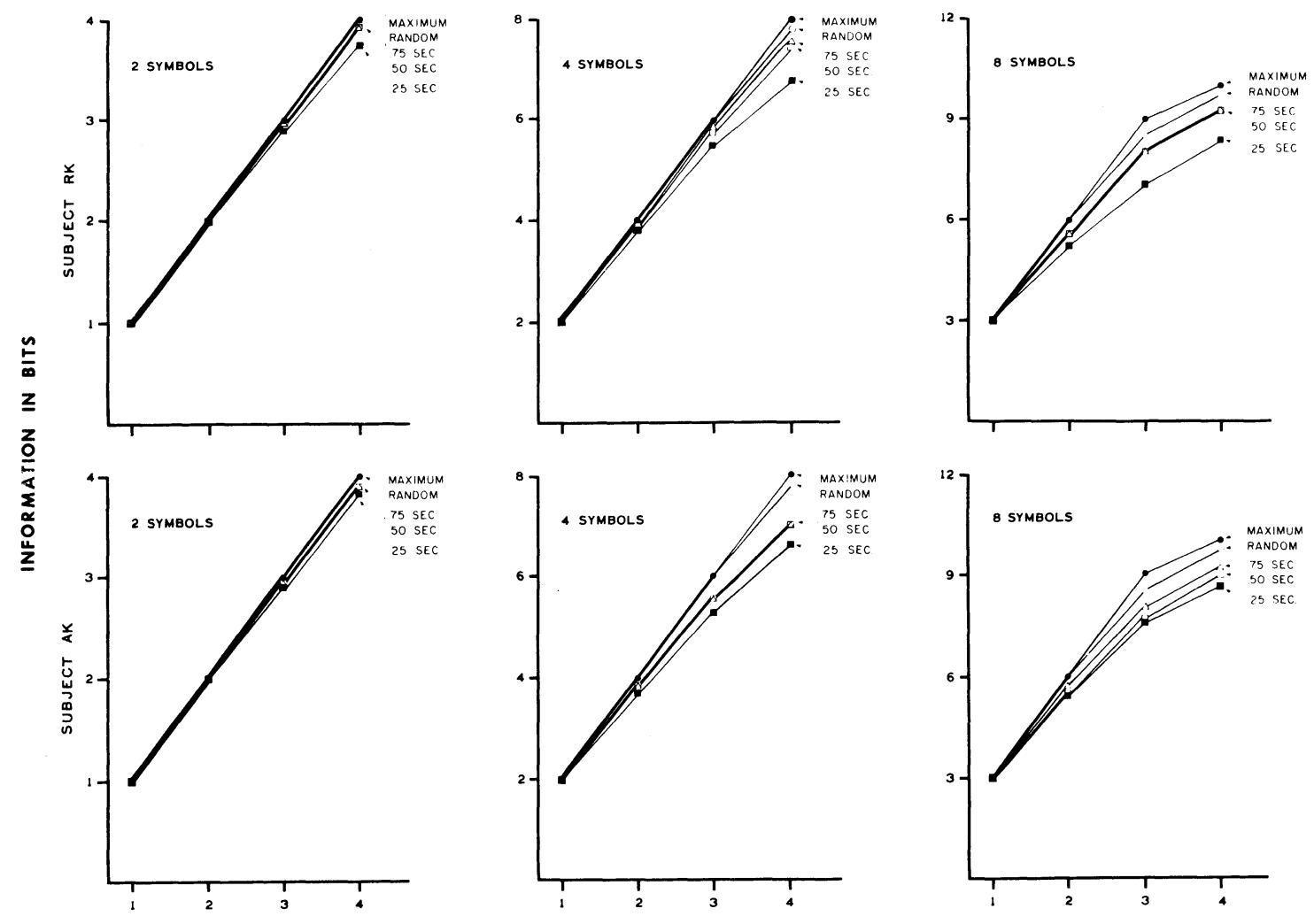

LENGTH OF RESPONSE SERIES ANALYZED

Fig. 1. Performance of the two Ss under all conditions of the randomization task.

sistent. Consequently, the data reported are means based on measures for separate weeks.

Figure 1 presents the data for Ss RK and AK under all experimental conditions. Each plot is for a given number of symbols (digits), and has information in bits on the ordinate and length of response series analyzed on the abscissa. The upper curve of each graph shows the maximum information possible in strings of length $1,2,3$, and 4 . The random curves give the information obtained when digits were drawn from a random number table. The remaining functions summarize performance when Ss' responses were produced every $.25, .50$, or $.75 \mathrm{sec}$.

Both Ss were proficient at randomizing. Responses uniformly contained from 84 to 100 percent of the information in the random series. When frequencies of single digits were counted (length of response series analyzed equals 1), obtained information was always equal to the maximum possible number of bits. Failures of randomization appeared only when longer response strings were analyzed, a finding which indicates the sequential character of biases in $\mathrm{Ss}^{\prime}$ responses.

The effects of the two experimental variables were in directions consonant with the findings of Baddeley. Figure 1 shows that attempts to randomize were less successful with more digits to be randomized and with less time per response. Though there were minimal differences in performance under the $.75 \mathrm{sec}$. and .50 sec. conditions, Ss quite clearly generated the least information when forced to respond every .25 sec. Over the ranges of the variables investigated it is apparent that Ss did not act as information generators of limited capacity. To illustrate, when responses were made every $.25 \mathrm{sec}$., response rate was triple what it was in the $.75 \mathrm{sec}$. condition. Though tripling response rate did reduce information per response (per digram, trigram, and tetragram-see Fig. 1), the faster rate by no means reduced information per response to one-third of its value in the $.75 \mathrm{sec}$. condition. In other words, forcing $\mathrm{Ss}$ to respond at the faster rate resulted not in less, but in considerably more information produced per unit time. The same general conclusion applies in the case of number of digits to be randomized-the larger the number of digits, the greater the amount of information produced per unit time.

\section{Referenees}

Attneave, F. Applications of information theory to psychology. New York: Holt, 1959.

Baddeley, A. D. Some factors influencing the generation of random letter sequences. Paper presented at the London meeting of the Experimental Psychology Society, January, 1962.

Tune, G. S. A brief survey of variables that influence random-generation, Percept. mot. Skills, 1964, 18, 705-710.

Miller, G. A. Note on the bias of information estimates. In $\mathrm{H}$. Quastler (Ed.), Information theory in psychology. Glencoe, Ill.: Free Press, 1955.

Note

1. This study was supported by National Science Foundation Grant GB-1600 awarded to the seccnd author and Kent State University. 